\title{
Otimização da densidade de semeadura em híbridos de arroz irrigado
}

\author{
Optimization of cultivar sowing density of rice hybrids
}

\section{Letícia Ramon de Medeiros ${ }^{1 *}$, Luis Osmar Braga Schuch ${ }^{1}$, Vitor Henrique Vaz Mondo², Ariano Martins de Magalhães Júnior ${ }^{2} \&$ Caio Sippel Dörr ${ }^{1}$}

\author{
1'Universidade Federal de Pelotas, Pelotas, RS, Brasil. *Autor para correspondência: leticiardemedeiros@gmail.com. \\ ${ }^{2}$ Empresa Brasileira de Pesquisa Agropecuária, Brasília, DF, Brasil.
}

Submissão: 21/09/2017 | Aceite: 13/06/2018

\begin{abstract}
RESUMO
O objetivo deste trabalho foi avaliar a produtividade e qualidade de grãos sob distintas densidades de semeadura em híbridos de arroz irrigado. Os experimentos foram conduzidos nos municípios de Capão do Leão e Capivari do Sul, no Rio Grande do Sul. Os híbridos BRSCIRAD 302 e BRSCIRAD AH703 CL foram analisados, nas densidades de semeadura de 10, 20, 30 e $40 \mathrm{~kg} \mathrm{ha}^{-1}$, para os caracteres: produtividade $\mathrm{e}$ componentes de produção de grãos, características agronômicas, qualidade industrial e comercial de grãos de arroz irrigado. Os dados foram submetidos à análise de variância e ao teste $\mathrm{F}$ utilizando-se para a comparação dos híbridos o teste de Tukey nível de significância de $5 \%$ e para densidade de semeadura foi aplicada a análise de regressão. A partir da densidade de semeadura de $20 \mathrm{~kg} \mathrm{ha}^{-1}$, não há efeito sobre a produtividade. A qualidade industrial de grãos dos híbridos não é influenciada pela variação na densidade de semeadura e a redução na densidade de semeadura para até $10 \mathrm{~kg} \mathrm{ha}^{-1}$ não prejudica a qualidade comercial dos grãos. Assim, é possível recomendar o cultivo de híbridos de arroz irrigado com densidades reduzidas de semeadura, a partir de $20 \mathrm{~kg} \mathrm{ha}^{-1}$, não afetando a produtividade de grãos e a qualidade dos grãos.
\end{abstract}

PALAVRAS-CHAVE: Oryza sativa L., população de plantas, qualidade de grãos, produção de arroz.

\begin{abstract}
The objective of this study was to evaluate the productivity and quality of grains under different sowing densities in irrigated rice hybrids. The hybrids BRSCIRAD 302 and BRSCIRAD AH703 CL were analyzed at sowing densities of 10, 20, 30 and $40 \mathrm{~kg} \mathrm{ha}^{-1}$, in the municipalities of Capão do Leão and Capivari do Sul, in the state of Rio Grande do Sul. The characteristics assessed were: productivity, components of grain production, agronomic characteristics, industrial and commercial quality of irrigated rice grains. The data were submitted to analysis of variance and $\mathrm{F}$ test, using for the comparison of hybrids the Tukey test at a $5 \%$ significance level, and for sowing, density regression analysis was applied. Sowing densities of $20 \mathrm{~kg}$ $\mathrm{ha}^{-1}$ and higher show no effect on productivity. The grain quality of hybrids is not influenced by the variation in sowing density, and reduction in sowing density up to $10 \mathrm{~kg} \mathrm{ha}^{-1}$ does not affect the commercial quality of the grains. Thus, it is possible to recommend the cultivation of irrigated rice hybrids with reduced sowing densities, starting from $20 \mathrm{~kg} \mathrm{ha}^{-1}$, without affecting grain yield and quality.
\end{abstract}

KEYWORDS: Oryza sativa L., plant population, grain quality, rice production.

\section{INTRODUÇÃO}

A produtividade média de arroz irrigado no Rio Grande do Sul e em Santa Catarina, principais estados produtores do Brasil, está acima de $7.000 \mathrm{~kg} \mathrm{ha}^{-1} \mathrm{e}$ as áreas estão estabilizadas nos últimos dez anos (SOSBAI 2014). Verifica-se ganho genético das cultivares convencionais e também avanços no manejo da cultura, no entanto, em comparação as décadas anteriores estes ganhos são considerados pequenos. Neste sentido, o uso da tecnologia híbrida em arroz, considerando suas características de alta produtividade, pode ser uma opção interessante para ultrapassar esse patamar de produtividade. Ainda, em um cenário um pouco mais amplo, onde a demanda por arroz mundialmente é crescente, sendo necessárias mais 116 milhões de toneladas até 2035 em relação a produção mundial de arroz em 2010 (GRiSP 2013), o uso de tecnologias que propiciem o aumento da produtividade na cultura do arroz é extremamente importante para alcançar essa demanda (AKHTER et al. 2007, QIN et al. 2013). 
Mundialmente, especialmente em países asiáticos, o uso de híbridos de arroz é bastante utilizado e apresenta acréscimos em produtividade entre 15 e $30 \%$, quando comparado a cultivares convencionais (TAN et al. 2002). No Brasil, a área cultivada com arroz híbrido também vem crescendo a cada ano, chegando a aproximadamente 9\% da área cultivada, ou 111 mil hectares (PLANETA ARROZ 2015), baseando-se principalmente nos acréscimos em produtividade de até $20 \%$ que essa tecnologia vem proporcionando (MIELEZRSKI et al. 2008).

A inserção dos híbridos de arroz no Brasil tem como objetivo explorar isoladamente a maior produtividade potencial em relação às cultivares convencionais existentes (COUTINHO et al. 2011), assim como, a estabilidade produtiva do híbrido em ambientes ou safras desfavoráveis. No entanto, as sementes híbridas de arroz, apesar do reconhecido valor da tecnologia, resultam em um alto investimento por parte do produtor rural devido suas especificidades na produção, o que vem dificultando a adoção de híbridos de arroz. Uma das formas de viabilizar o seu uso, tornando-a mais competitiva perante as cultivares convencionais é a redução da densidade de semeadura dos mesmos. Isso é decorrente dos efeitos da heterose em híbridos, que mesmo em baixas populações de plantas garantem altas produtividades a campo (PARISOTTO et al. 2013), e que pode se traduzir em um menor investimento e redução do custo de produção.

Atualmente, a densidade de semeadura em áreas para arroz irrigado, é em torno de 80 a $120 \mathrm{~kg} \mathrm{ha}^{-1}$, com cultivares convencionais (SOSBAI 2014). Já, para a tecnologia de híbridos de arroz, a taxa de semeadura recomendada é em torno de $40 \mathrm{~kg} \mathrm{ha}^{-1}$ (SOSBAI 2014), no entanto, com custo por quilograma de sementes, até 10 vezes maior do que cultivares convencionais. No entanto, essas taxas de consumo de sementes podem ser extremamente reduzidas, baseando-se em sistemas de semeadura indireta, como ocorre com a preparação de mudas e o transplante no campo, onde se chega a utilizar em torno de $15 \mathrm{~kg} \mathrm{ha}^{-1}$, ou em sistemas como o "System of Rice Intensification" - SRI (UPHOFF \& RANDRIAMIHARISOA 2002), com consumos reduzidos de sementes de 1 a $3,5 \mathrm{~kg} \mathrm{ha}^{-1}$, com a manutenção de altos patamares de produtividade. De acordo com WANG et al. (2014), pesquisadores de arroz na China têm enfatizado a importância de regular as relações compensatórias e competitivas entre plantas para aumentar a produtividade de grãos, visto que, o custosde produção pode ser minimizado com a semeadura em baixas densidades de plantas (LIN et al. 2009) e, até trazer maior competitividade a tecnologia de arroz híbrido.

Assim, o objetivo deste trabalho foi avaliar a produtividade e qualidade dos grãos sob distintas densidades de semeadura em híbridos de arroz irrigado.

\section{MATERIAL E MÉTODOS}

Os experimentos foram conduzidos a campo, um na Estação Experimental de Terras Baixas da Embrapa Clima Temperado, município de Capão do Leão, RS, $31^{\circ} 52^{\prime} 00^{\prime \prime}$ de latitude sul e $52^{\circ} 21^{\prime} 24^{\prime \prime}$ longitude oeste e altitude de $14 \mathrm{~m}$ aproximadamente. $\mathrm{O}$ clima da região, de acordo com a classificação climática de Köppen, é do tipo Cfa, temperado quente. O solo é classificado como Planossolo Háplico eutrófico típico. O outro foi no município de Capivari do Sul, RS, Fazenda Capão de Fora, $30^{\circ} 08^{\prime} 42^{\prime \prime}$ de latitude sul 50³0'52" longitude oeste, altitude $9 \mathrm{~m}$. O clima do tipo Cfa, subtropical úmido (classificação climática de Köppen) e solo classificado como Planossolo Háplico Distrófico espessarênico. As características físico-químicas dos solos

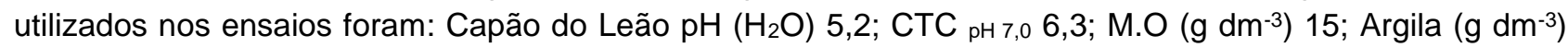
190 e Classe textural 4, Capivari do Sul pH $\left(\mathrm{H}_{2} \mathrm{O}\right)$ 4,9; CTC $\mathrm{pH} 7,0$ 8,3; M.O (g dm$\left.{ }^{-3}\right)$ 18; Argila $\left(\mathrm{g} \mathrm{dm}^{-3}\right) 140$ Classe textural 4. Ambos experimentos foram conduzidos na safra 2014/2015.

O delineamento experimental utilizado foi o de blocos ao acaso, com três repetições, em esquema fatorial $2 \times 4$, composto por dois híbridos de arroz e quatro densidades de semeadura. Foram avaliados os híbridos de arroz irrigado, BRSCIRAD 302 (lançado e protegido pela parceria Embrapa - CIRAD) e BRSCIRAD AH703 CL (desenvolvido pela parceria Embrapa - CIRAD, o qual, encontra-se nas etapas finais de avaliação em ensaios de rendimento), sendo semeados em quatro densidades de semeadura 10, 20, 30, $40 \mathrm{~kg} \mathrm{ha}^{-1}$.

Os experimentos foram conduzidos no sistema de cultivo convencional, sendo a semeadura realizada mecanicamente com semeadora de parcelas, as quais eram compostas por cinco linhas de cinco metros, espaçadas de $0,2 \mathrm{~m}$ entre si. Com o intuito de exclusão dos efeitos de bordadura foram colhidas as três linhas centrais, eliminando-se $0,5 \mathrm{~m}$ das suas extremidades, totalizando área útil equivalente a 2,4 $\mathrm{m}^{2}$ por unidade experimental.

A regulagem da semeadora para distribuição de sementes é fixa, logo, para variar a densidade de semeadura e obter-se homogeneidade na distribuição de sementes, utilizou-se 0 artifício da adição de sementes mortas às amostras. As sementes inviáveis foram colocadas, posteriormente a embebição por 24 h em água, na estufa por $72 \mathrm{~h}$ a $78^{\circ} \mathrm{C}$ e após este tratamento submetidas ao teste de germinação conforme 
as Regras para Análise de Sementes (Brasil, 2009) para confirmação da sua inviabilidade. Ainda, a semeadura foi realizada utilizando taxa de semeadura acrescida de $10 \%$ em relação às densidades desejadas, a fim de garantir as populações desejadas e após a contagem da população foi realizado o desbaste manual para adequação das mesmas.

A adubação foi realizada conforme a interpretação da análise de solo e as práticas de manejo da cultura realizadas de acordo com as recomendações técnicas para o cultivo de arroz irrigado no Sul do Brasil (SOSBAI 2014), objetivando parcelas livres de plantas daninhas, pragas e doenças.

Quanto ao desempenho da cultura, foram realizadas após a colheita, as seguintes avaliações: produtividade de grãos, número de grãos por panículas, massa de 1000 grãos, percentagem de grãos imaturos, número de panículas por metro quadrado, número de panículas por planta e percentual de espiguetas estéreis. A produtividade foi determinada pela colheita das áreas úteis das parcelas e transformado seu peso em kg ha-1, corrigido para 13\% de umidade. Foram coletadas, ao acaso, 25 panículas por parcela para avaliar a contagem do número de grãos por panículas. A massa de 1000 grãos foi determinada pela pesagem de uma amostra de 1000 grãos pertencente à área útil da parcela. A percentagem de grãos imaturos foi determinada através da separação visual e contagem do número de grãos verdes na amostra de 1000 grãos e os resultados expressos em percentagem. Na maturação foram contadas as plantas e as panículas presentes em 2 metros de linha determinando-se assim, o número de panículas por metro quadrado e número de panículas por planta. O percentual de espiguetas estéreis por panículas foi determinado a partir da separação, com o auxílio de um soprador de sementes, e contagem das espiguetas estéreis.

Após a colheita, procederam-se as avaliações quanto a qualidade industrial de grãos por meio de determinação da renda total do benefício, rendimento de grãos inteiros e quebrados. Para tanto utilizou-se amostras de $100 \mathrm{~g}$ de grãos com casca a $13 \%$ de umidade, as quais foram submetidas por um minuto ao engenho de provas SUZUKI, modelo MT, para descasque e polimento desses grãos e o resultado expresso em percentagem.

Ainda, foi determinada a qualidade física dos grãos de arroz por meio da avaliação do grau de opacidade dos grãos (grãos gessados), sendo o mesmo classificado em três frações de ocorrência de área opaca na superfície dos grãos: menor que $1 / 3$ de área opaca, entre 1/3-2/3 e maior que $2 / 3$ de área opaca. A classificação do grau de opacidade foi realizada visualmente através da separação manual dos grãos utilizando a fração de renda total do benefício.

Os dados obtidos foram submetidos à análise de variância e ao teste $\mathrm{F}$ a $5 \%$ de probabilidade. Quando significativos, para o fator qualitativo, híbridos, utilizou-se para comparação das médias o teste de Tukey a $5 \%$ e, para o fator quantitativo, densidade de semeadura foi aplicada a análise de regressão.

\section{RESULTADOS E DISCUSSÃO}

Observando-se os valores dos quadrados médios juntamente com 0 teste $F$ de significância apresentados na Tabela 1, para ambas as localidades em que o experimento foi desenvolvido, constatou-se que não ocorreu interação significativa entre os fatores híbridos de arroz e densidades de semeadura para variáveis analisadas. Observa-se ainda que, para o experimento conduzido em Capão do Leão, os híbridos diferiram entre si para os caracteres de número de panículas por metro quadrado, número de panículas por planta, número de grãos por panícula e massa de mil grãos, enquanto que a variação na densidade de semeadura afetou somente a produtividade e o número de panículas por planta. A percentagem de grãos verdes não foi afetada por nenhum dos fatores analisados.

Em Capão do Leão, a produtividade apresentou acréscimos com o aumento da densidade de semeadura até densidades em torno de $20 \mathrm{~kg} \mathrm{ha}^{-1}$, não sofrendo acréscimos para densidades superiores (Figura 1A). Esse comportamento pode ser explicado pela extrema capacidade de compensação nos componentes do rendimento apresentado por híbridos de arroz, como pode ser observado pelo acréscimo no número de panículas por planta em contraponto à redução na densidade de semeadura (Figura 1B).

Resultados semelhantes foram observados por HÖFS et al. (2004), que constataram o efeito da plasticidade do arroz em produzir um maior número de panículas por planta com a redução na densidade de semeadura, sem demonstrar variação na produtividade de grãos por área. A massa de mil grãos não foi afetada pela variação na densidade de semeadura (Tabela 1), sendo esse resultado semelhante aos encontrados por HÖFS et al. (2004) e CRUSCIOL et al. (2000).

Observando-se os valores dos quadrados médios juntamente com o teste $\mathrm{F}$ para o município de Capivari do Sul (Tabela 1), constatou-se que, os híbridos diferiram entre si para a massa de mil grãos, enquanto que a variação na densidade de semeadura afetou a produtividade média, o número de panículas 
por planta e por área, e o número de grãos por panícula. A percentagem de grãos verdes não foi afetada pelos fatores analisados.

Tabela 1. Resumo da análise de variância para produtividade, componentes de rendimento e características agronômicas de dois híbridos de arroz irrigado, submetidos a quatro densidades de semeadura, nos municípios de Capão do Leão e Capivari do Sul, RS, safra 2014/15.

Table 1. Summary of the analysis of variance for productivity, yield components and agronomic characteristics of two irrigated rice hybrids subjected to four sowing densities, in the municipalities of Capão do Leão and Capivari do Sul, RS, harvest 2014/15.

\begin{tabular}{|c|c|c|c|c|}
\hline \multirow[b]{2}{*}{ Capão do Leão } & \multicolumn{3}{|c|}{ Quadrados Médios } & \multirow[b]{2}{*}{ CV \% } \\
\hline & Híbridos & Densidades & Interação & \\
\hline Produtividade & $1355175^{\mathrm{NS}}$ & $1306345^{\star}$ & $691041,8^{\mathrm{NS}}$ & 6,32 \\
\hline Panículas $\mathrm{m}^{-2}$ & $9700,26^{*}$ & $486,37^{\mathrm{NS}}$ & $1140,53^{\mathrm{NS}}$ & 9,29 \\
\hline Panículas planta ${ }^{-1}$ & $1,57^{*}$ & $50,27^{\star *}$ & $0,24^{\mathrm{NS}}$ & 12,17 \\
\hline Grãos panícula $^{-1}$ & $1908,16^{*}$ & $35,44^{\mathrm{NS}}$ & $160,27^{\mathrm{NS}}$ & 14,08 \\
\hline Massa de 1000 grãos (g) & $8,98^{\star *}$ & $0,05^{\mathrm{NS}}$ & $0,16^{\mathrm{NS}}$ & 1,96 \\
\hline \multirow[t]{2}{*}{ Grãos imaturos (\%) } & $36,50^{\mathrm{NS}}$ & $5,95^{\mathrm{NS}}$ & $13,49^{\mathrm{NS}}$ & 22,89 \\
\hline & \multicolumn{3}{|c|}{ Quadrados Médios } & \\
\hline Capivari do Sul & Híbridos & Densidades & Interação & CV \% \\
\hline Produtividade & $2698,82^{\mathrm{NS}}$ & $1264292^{*}$ & $525569^{\text {NS }}$ & 6,46 \\
\hline Panículas $\mathrm{m}^{-2}$ & $625,26^{\mathrm{NS}}$ & $13373,87^{\star \star}$ & $899,56^{\mathrm{NS}}$ & 10,36 \\
\hline Panículas planta ${ }^{-1}$ & $0,1^{\mathrm{NS}}$ & $24,48^{\star \star}$ & $0,12^{\mathrm{NS}}$ & 11,35 \\
\hline 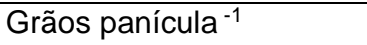 & $204,16^{\mathrm{NS}}$ & $1238,94^{\star \star}$ & $202,27^{\mathrm{NS}}$ & 9,67 \\
\hline Massa de 1000 grãos (g) & $36,32^{* *}$ & $0,51^{\mathrm{NS}}$ & $0,18^{\mathrm{NS}}$ & 1,89 \\
\hline Grãos imaturos (\%) & $38,25^{\mathrm{NS}}$ & $23,91^{\mathrm{NS}}$ & $4,26^{\mathrm{NS}}$ & 33,96 \\
\hline
\end{tabular}

NS - F não significativo; ${ }^{*} \mathrm{~F}$ significativo ao nível de $5 \%$ de probabilidade; ${ }^{*} \mathrm{~F}$ significativo ao nível de $1 \%$ de probabilidade.

A produtividade apresentou acréscimos em torno da densidade de $20 \mathrm{~kg} \mathrm{ha}^{-1}$ mantendo-se estável a partir dessa densidade (Figura 2A). Desempenho similar pôde ser observado para o número de panículas por metro quadrado (Figura 2B), demonstrando acréscimos até densidades em torno de $20 \mathrm{~kg} \mathrm{ha}^{-1}$. Para populações inferiores a $20 \mathrm{~kg} \mathrm{ha}^{-1}$, porém, o aumento no número de panículas por planta e no número de grãos por panícula não foi capaz de manter elevada a produtividade média de grãos, proporcionando redução da mesma.

A

B

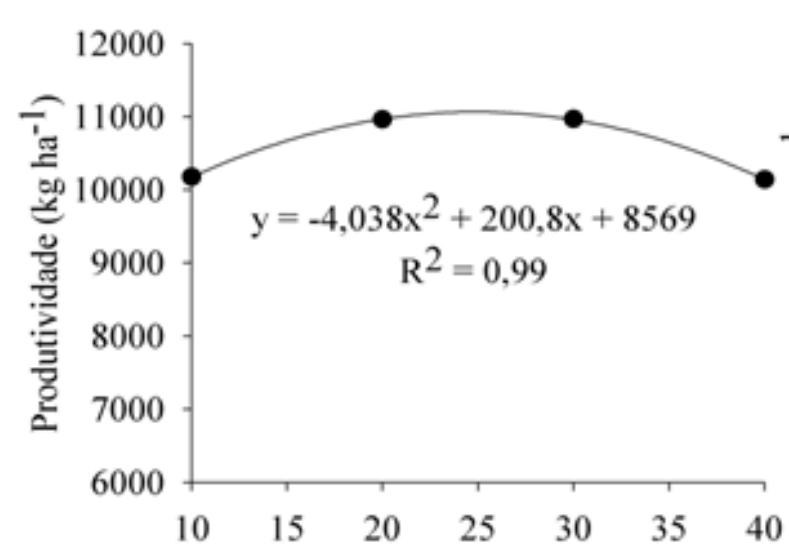

Densidade de semeadura $\left(\mathrm{kg} \mathrm{ha}^{-1}\right)$

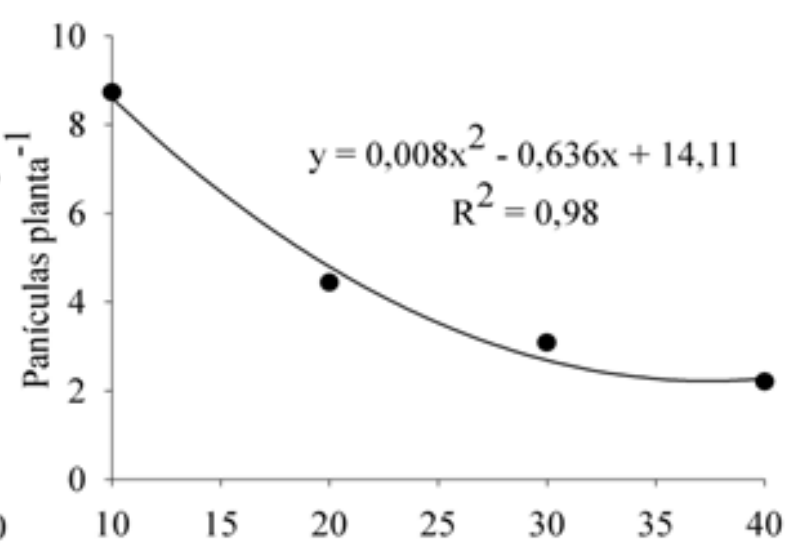

Densidade de semeadura $\left(\mathrm{kg} \mathrm{ha}^{-1}\right)$

Figura 1. Produtividade $\left(\mathrm{kg} \mathrm{ha}^{-1}\right)(\mathrm{A})$, número de panículas por planta $(\mathrm{B})$ de híbridos de arroz irrigado, em função da variação na densidade de semeadura, no município de Capão do Leão, RS, 2014/15.

Figure 1. Productivity $\left(\mathrm{kg} \mathrm{ha}^{-1}\right)(A)$, number of panicles per plant $(B)$ of irrigated rice hybrids, due to variation in sowing density, in the municipality of Capão do Leão, RS, 2014/15. 
Desempenho semelhante para a produtividade média de grãos também foi observada no município de Capão do Leão para densidades inferiores a $20 \mathrm{~kg} \mathrm{ha}^{-1}$. Compensações nos componentes número de panículas por metro quadrado, número de panículas por planta e número de grãos por panículas, em função da redução da densidade de semeadura, também, foram observadas por HÖFS et al. (2004) em cultivares convencionais de arroz irrigado, que não demonstraram alterações no rendimento de grãos.
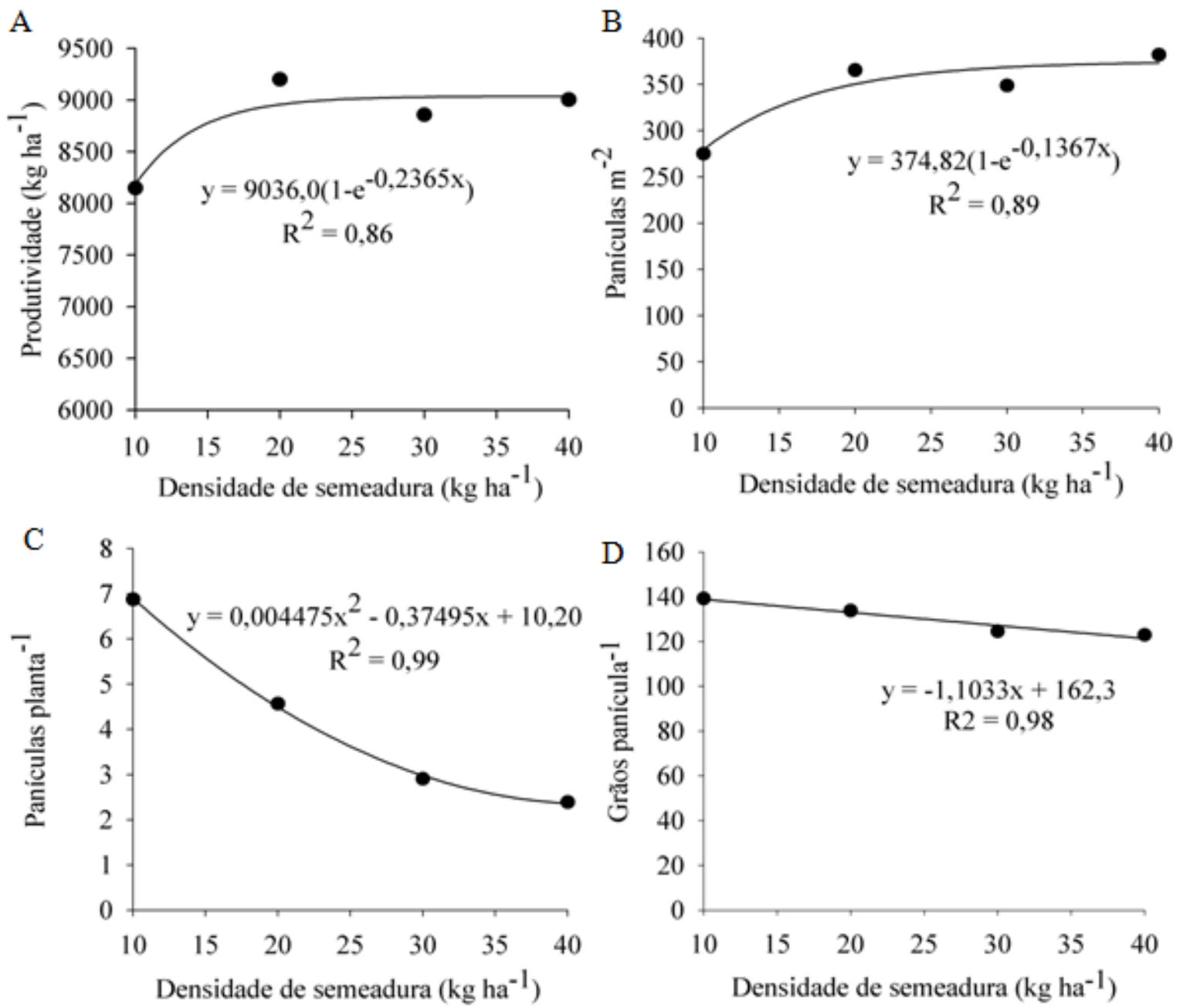

Figura 2. Produtividade ( $\left.\mathrm{kg} \mathrm{ha}^{-1}\right)(\mathrm{A})$, número de panículas por $\mathrm{m}^{2}(\mathrm{~B})$, número de panículas por planta (C), número de grãos por panícula (D) de híbridos de arroz irrigado, em função da variação na densidade de semeadura, no município de Capivari do Sul, RS, 2014/15.

Figure 2 Productivity ( $\left.\mathrm{kg} \mathrm{ha}^{-1}\right)$, number of panicles per $\mathrm{m}^{2}(B)$, number of panicles per plant $(C)$, number of grains per panicle $(D)$ of irrigated rice hybrids, per sowing density, in the municipality of Capivari do Sul, RS, 2014/15.

Observando-se o maior número de panículas por planta com a redução da densidade de semeadura (Figura 2C), percebe-se que este representa a capacidade de compensação no número de panículas emitidas por área. Quanto ao número de grãos por panícula (Figura 2D), o resultado observado em Capivari do Sul é semelhante ao constatado por LIMA et al. (2010), onde o número de espiguetas granadas por panícula dos colmos principais e dos afilhos reduziu com o aumento da densidade de semeadura.

Os dois híbridos apresentaram resposta semelhante entre si para a variação na densidade de semeadura, e não diferiram entre si para a produtividade média de grãos em nenhum dos locais.

Para a qualidade industrial de grãos (Tabela 2), observou-se que não houve interação entre os fatores e nem efeito de densidade de semeadura para os resultados obtidos nos municípios de Capão do Leão e Capivari do Sul. Para o fator híbridos, em Capão do Leão, houve significância estatística para as variáveis porcentagem de grãos inteiros e porcentagem de grãos quebrados, enquanto que em Capivari do Sul, a análise da variância mostra que não houve efeito desse fator para todas as variáveis. 
Tabela 2. Resumo da análise de variância para a qualidade industrial e comercial de dois híbridos de arroz irrigado, submetidos a quatro densidades de semeadura, nos municípios de Capão do Leão e Capivari do Sul, RS, 2014/15.

Table 2. Summary of the analysis of variance for the industrial and commercial quality of two hybrids of irrigated rice, subjected to four sowing densities, in the municipalities of Capão do Leão and Capivari do Sul, RS, 2014/15.

Qualidade industrial

\begin{tabular}{lllll}
\hline \multirow{2}{*}{ Capão do Leão } & \multicolumn{4}{c}{ Quadrados Médios } \\
\cline { 2 - 4 } & Híbridos & Densidades & Interação & CV \% \\
\hline Renda do benefício (\%) & $2,88^{\mathrm{NS}}$ & $1,04^{\mathrm{NS}}$ & $0,29^{\mathrm{NS}}$ & 1,32 \\
Grãos inteiros (\%) & $19,06^{*}$ & $1,25^{\mathrm{NS}}$ & $2,86^{\mathrm{NS}}$ & 2,73 \\
Grãos quebrados (\%) & $7,13^{*}$ & $0,84^{\mathrm{NS}}$ & $1,76^{\mathrm{NS}}$ & 20,47 \\
\hline \multirow{3}{*}{ Capivari do Sul } & \multicolumn{4}{c}{ Quadrados Médios } \\
\cline { 2 - 4 } Renda do benefício (\%) & Híbridos & Densidades & Interação & CV \% \\
Grãos inteiros (\%) & $3,62^{\mathrm{NS}}$ & $0,64^{\mathrm{NS}}$ & $0,64^{\mathrm{NS}}$ & 1,98 \\
Grãos quebrados (\%) & $1,60^{\mathrm{NS}}$ & $2,53^{\mathrm{NS}}$ & $2,81^{\mathrm{NS}}$ & 5,26 \\
\hline
\end{tabular}

Qualidade comercial

\begin{tabular}{|c|c|c|c|c|}
\hline \multirow[b]{2}{*}{ Capão do Leão } & \multicolumn{3}{|c|}{ Quadrados Médios } & \multirow[b]{2}{*}{ CV \% } \\
\hline & Híbridos & Densidades & Interação & \\
\hline Menor que $1 / 3$ & $0,97^{\mathrm{NS}}$ & $0,29^{N S}$ & $1,24^{*}$ & 46,53 \\
\hline Entre $1 / 3$ e $2 / 3$ & $7,37^{\star}$ & $0,88^{\mathrm{NS}}$ & $1,36^{\star}$ & 25,14 \\
\hline \multirow[t]{2}{*}{ Maior que $2 / 3$} & $0,47^{N S}$ & $0,13^{\mathrm{NS}}$ & $0,02^{\mathrm{NS}}$ & 41,38 \\
\hline & \multicolumn{3}{|c|}{ Quadrados Médios } & \\
\hline Capivari do Sul & Híbridos & Densidades & Interação & CV \% \\
\hline Menor que $1 / 3$ & $0,05^{\mathrm{NS}}$ & $0,12^{\mathrm{NS}}$ & $0,16^{\mathrm{NS}}$ & 50,95 \\
\hline Entre $1 / 3$ e $2 / 3$ & $0,18^{\mathrm{NS}}$ & $0,14^{\mathrm{NS}}$ & $0,25^{\mathrm{NS}}$ & 20,75 \\
\hline Maior que $2 / 3$ & $0,03^{\mathrm{NS}}$ & $0,09^{N S}$ & $0,03^{\mathrm{NS}}$ & 29,59 \\
\hline
\end{tabular}

NS - F não significativo; * F significativo ao nível de $5 \%$ de probabilidade.

Dessa forma constata-se que a variação na densidade de semeadura não influenciou a qualidade industrial dos grãos em nenhum dos locais testados, fato também observado por GOULART et al. (2015), em híbridos de arroz irrigado submetido a diferentes arranjos de plantas e densidades de semeadura.

O híbrido BRSCIRAD 302 apresentou maior percentagem de grãos inteiros e menor percentagem de grãos quebrados no município de Capão do Leão, demonstrando uma maior qualidade industrial do que o híbrido BRSCIRAD AH703 CL (Tabela 3), não diferindo para essas características no município de Capivari do Sul. Essa diferença entre os híbridos pode ser atribuída a características genéticas dos materiais, sendo estas devidas, entre outros fatores, pela composição química dos grãos, presença de centro branco nos grãos, grãos gessados e amplitude no teor de água (MARCHEZAN et al. 1993).

A avaliação da qualidade comercial dos grãos em função do grau de opacidade (Tabela 2) demonstra que a interação entre os fatores híbridos e densidades de semeadura apresentou significância estatística para o grau de opacidade menor que 1/3 e entre 1/3 e 2/3 da superfície dos grãos, no município do Capão do Leão. Para as demais variáveis não foi observado efeito dos fatores em estudo (Tabela 2). Para o município de Capivari do Sul não se observou nenhum efeito dos fatores considerados para todas as variáveis. Vale ressaltar que grãos que apresentam pequenos pontos de gessamento nos grãos reduzem o valor comercial do mesmo (SOFIATTI et al. 2006).

Para percentagem de grãos com grau de opacidade (Figura 3), observou-se que resultados menores que $1 / 3$ dos grãos e entre $1 / 3$ e 2/3 dos grãos sofreram acréscimos com o aumento da densidade de semeadura para o híbrido BRSCIRAD AH703 CL, no município de Capão do Leão, demonstrando que a redução na densidade favorece na diminuição da percentagem de grãos com algum grau de opacidade. Por outro lado, o híbrido BRSCIRAD 302 não foi afetado pela variação na densidade de semeadura para essas características.

A densidade de semeadura pode exercer influência sobre a qualidade dos grãos, sendo que a alta densidade pode reduzir significativamente a razão de grão não polido e polido, teor de proteína, diminuição da transparência dos grãos, enquanto que, aumenta a proporção de área opaca dos grãos e teor de amilose 
e consistência de grãos de arroz (CHEN et al. 2003). No entanto, a densidade de plantas não afetou o percentual que grãos opacos em três populações de plantas variando entre 16,32 e 48 plantas por metro quadrado (AHMAD et al. 2009).

Tabela 3. Qualidade industrial e comercial de híbridos de arroz irrigado, BRSCIRAD 302 e BRSCIRAD AH703 CL, nos municípios de Capão do Leão e Capivari do Sul, RS, 2014/15.

Table 3. Industrial and commercial quality of irrigated rice hybrids, BRSCIRAD 302 and BRSCIRAD AH703 CL, in the municipalities of Capão do Leão and Capivari do Sul, RS, 2014/15.

\begin{tabular}{|c|c|c|c|}
\hline \multicolumn{4}{|c|}{$\begin{array}{c}\text { Qualidade industrial } \\
\end{array}$} \\
\hline Capão do Leão & $\begin{array}{c}\text { Renda total do benefício } \\
(\%)\end{array}$ & Grãos inteiros (\%) & Grãos quebrados (\%) \\
\hline BRSCIRAD 302 & 69,87 a & 64,83 a & $5,04 \mathrm{~b}$ \\
\hline BRSCIRAD AH703 CL & $69,18 \mathrm{a}$ & $63,04 \mathrm{~b}$ & $6,13 \mathrm{a}$ \\
\hline Capivari do Sul & $\begin{array}{c}\text { Renda total do benefício } \\
(\%)\end{array}$ & Grãos inteiros (\%) & Grãos quebrados (\%) \\
\hline BRSCIRAD 302 & $69,22 \mathrm{a}$ & $63,21 \mathrm{a}$ & $6,01 \mathrm{a}$ \\
\hline BRSCIRAD AH703 CL & $70,00 \mathrm{a}$ & $63,72 \mathrm{a}$ & $6,27 \mathrm{a}$ \\
\hline \multicolumn{4}{|c|}{ Qualidade comercial } \\
\hline Capão do Leão & Menor que $1 / 3(\%)$ & Entre $1 / 3$ e $2 / 3(\%)$ & Maior que 2/3 (\%) \\
\hline BRS CIRAD 302 & 1,37 NS & $2,72 b$ & $1,38 \mathrm{NS}$ \\
\hline BRSCIRAD AH703 CL & 1,96 NS & $4,32 \mathrm{a}$ & $1,78^{\mathrm{NS}}$ \\
\hline Capivari do Sul & Menor que $1 / 3(\%)$ & Entre $1 / 3$ e $2 / 3(\%)$ & Maior que 2/3 (\%) \\
\hline BRS CIRAD 302 & $1,19 a$ & $1,83 \mathrm{a}$ & $0,99 \mathrm{a}$ \\
\hline BRSCIRAD AH703 CL & $1,36 \mathrm{a}$ & $2,14 \mathrm{a}$ & $0,89 \mathrm{a}$ \\
\hline
\end{tabular}
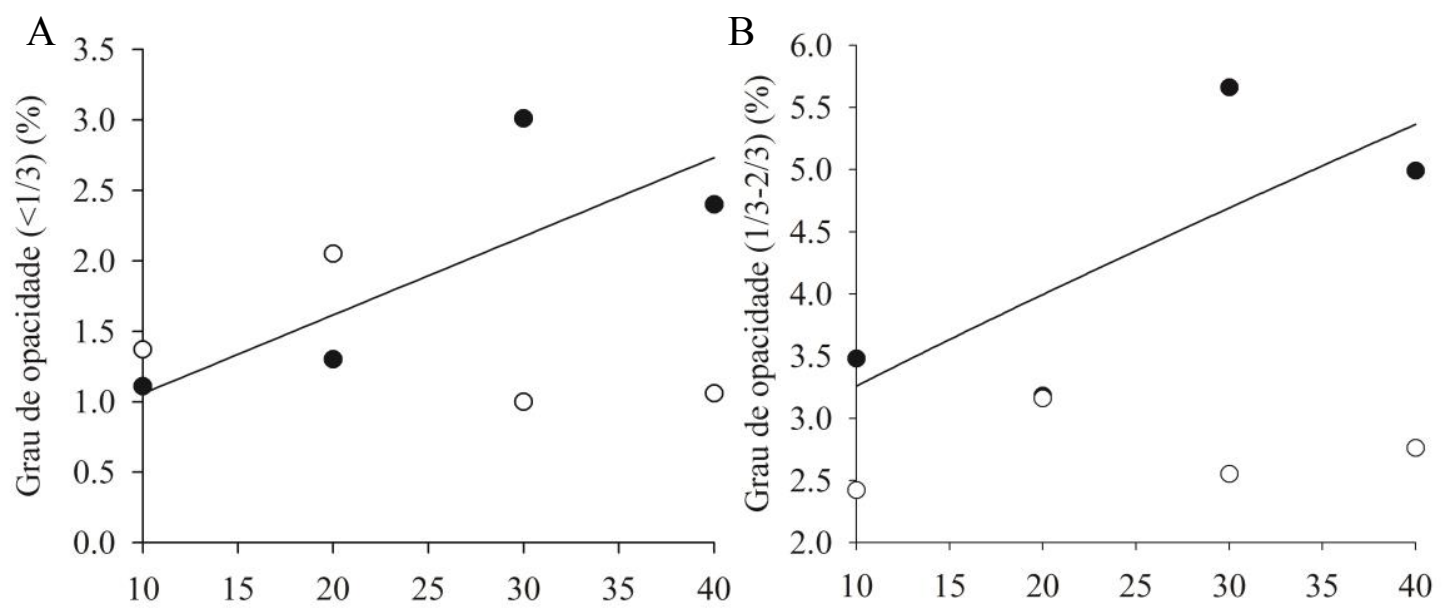

\footnotetext{
Densidade de semeadura $\left(\mathrm{kg} \mathrm{ha}^{-1}\right)$

- BRS CIRAD AH $703 \mathrm{CL} y=0,070 \mathrm{x}+2,57$ $\mathrm{R} 2=0,5$

B BRS CIRAD $302 \mathrm{y}=\mathrm{NS}$
}

Densidade de semeadura $\left(\mathrm{kg} \mathrm{ha}^{-1}\right)$

- $\quad$ BRS CIRAD AH 703 CL y=0,070x $+2,57$ $\mathrm{R} 2=0,5$

B BRS CIRAD $302 \mathrm{y}=\mathrm{NS}$

Figura 3. Qualidade comercial de híbridos de arroz irrigado, representada pela percentagem de grãos com graus de opacidade $<1 / 3(A)$ e entre 1/3-2/3 (B) dos grãos, em função da variação na densidade de semeadura, no município de Capão do Leão, RS, 2014/15.

Figure 3. Commercial quality of irrigated rice hybrids, represented by the percentage of grains with degrees of opacity $<1 / 3(A)$ and between $1 / 3-2 / 3(B)$ of the grains, according to variation in sowing density, in the municipality of Capão do Leão, RS, 2014/15.

De forma geral, os resultados obtidos com a variação da densidade de semeadura demonstraram que 
é possível reduzir a recomendação de densidade de semeadura para híbridos de arroz avaliados nesse trabalho, para taxas 50\% inferiores as trabalhadas atualmente, ou seja, de $40 \mathrm{~kg} \mathrm{ha}^{-1}$ para $20 \mathrm{~kg} \mathrm{ha}^{-1}$, sem perdas em produtividade, qualidade industrial e comercial de grãos. Isso demonstra um grande avanço no conhecimento e pode ter aplicações práticas para essa tecnologia, aumentando a sua competitividade e ser fator significativo no aumento da adoção de híbridos de arroz na agricultura brasileira.

\title{
CONCLUSÃO
}

A otimização da densidade de semeadura dos híbridos de arroz BRSCIRAD 302 e BRSCIRAD AH703 $\mathrm{CL}$ é permitida até valores de $20 \mathrm{~kg} \mathrm{ha}^{-1}$, mantendo altos níveis de produtividade e qualidade industrial de grãos.

\section{AGRADECIMENTOS}

\author{
A EMBRAPA, UFPEL E CAPES.
}

\section{REFERÊNCIAS}

AHMAD S et al. 2009. Morphological and quality parameters of Oryza sativa L. as affected by population dynamics, nitrogen fertilization and irrigation regimes. Pakistan Journal of Botany 41: 1259-1269.

AKHTER M et al. 2007. Hybrid rice research and developments in Pakistan. Asian Journal of Plant Sciences 6: 795-801. BRASIL. 2009. Ministério da Agricultura, Pecuária e Abastecimento. Regras para análise de sementes. Brasília: MAPA/ACS. 399p.

CHEN F et al. 2003. Improving rice quality through crop and resource management. In: MEW TW et al. (Eds.). Rice science: innovations and impact for livelihood. Beijing, China: Proceedings of the International Rice Research Conference. p. 479486.

COUTINHO AR et al. 2011. Redução da densidade de plantio como alternativa para o aumento da competitividade de cultivares de arroz híbrido no mercado gaúcho. In: VII Congresso Brasileiro do Arroz Irrigado: Racionalizando recursos e ampliando oportunidades. Resumos.... Balneário Camboriú: SOSBAI. p.793-796.

CRUSCIOL CAC et al. 2000. Produtividade do arroz irrigado por aspersão em função do espaçamento e da densidade de semeadura. Pesquisa Agropecuária Brasileira 35: 1093-1100.

GOULART E da $\mathrm{S}$ et al. 2015. Performance of rice hybrids determined by different planting arrangements. Ciencia e Inestigacíon Agraria 42: 75-83.

GRiSP. 2013. Global Rice Science Partnership. Rice almanac, 4th edition. Los Baños (Philippines): International Rice Research Institute. 283p.

HÖFS A et al. 2004. Efeito da qualidade fisiológica das sementes e da densidade de semeadura sobre o rendimento de grãos e qualidade industrial em arroz. Revista Brasileira de Sementes 26: 54-62.

LIN XQ et al. 2009. Effect of plant density and nitrogen fertilizer rates on grain yield and nitrogen uptake of hybrid rice (Oryza sativa L.) Journal of Agricultural Biotechnology and Sustainable Development 1: 44-53.

LIMA E do V et al. 2010. Participação do colmo principal e dos afilhos na produtividade do arroz irrigado, em função da densidade de semeadura. Bragantia 69: 387-393.

MARCHEZAN E et al. 1993. Relações entre a época de semeadura, de colheita e rendimento de grãos inteiros de cultivares de arroz irrigado. Pesquisa Agropecuária Brasileira 28: 843-848.

MIELEZRSKI $F$ et al. 2008. Desempenho em campo de plantas isoladas de arroz híbrido em função da qualidade fisiológica das sementes. Revista Brasileira de Sementes 30: 139-144.

PARISOTTO E. et al. 2013. Avaliação do rendimento de grãos em função de diferentes densidades de semeadura em quatro híbridos de arroz. In: Congresso Brasileiro de Arroz Irrigado, 8. Anais.... Santa Maria: UFSM. p. 1324-1327.

PLANETA ARROZ. 2015. Qualidade do arroz produzido no Brasil ajuda a conquistar novos mercados. Disponível em: http://www.planetaarroz.com/site/noticias_detalhe.php?idNoticia=13658. Acesso em: 04 Set. 2015.

QIN J et al. 2013. Integrated nutrient, water and other agronomic options to enhance rice grain yield and $\mathrm{N}$ use efficiency in double-season rice crop. Field Crops Research 148: 15-23.

SOFIATTI $V$ et al. 2006. Efeitos de regulador de crescimento, controle de doenças e densidade de semeadura na qualidade industrial de grãos de arroz. Ciência Rural 36: 418-423.

SOSBAI. 2014. Sociedade Sul-Brasileira de Arroz Irrigado. Arroz irrigado: recomendações técnicas da pesquisa para o Sul do Brasil. XXX Reunião Técnica da Cultura do Arroz Irrigado. Bento Gonçalves: SOSBAI. 192p.

TAN Y et al. 2002. Physicochemical properties of an elite rice hybrid. Journal of the Science of Food and Agriculture 82 : 1628-1636.

UPHOFF N \& RANDRIAMIHARISOA R. 2002. Reducing water use in irrigated rice production with the Madagascar System of Rice Intensification (SRI). In: BOUMAN BAM et al. (Eds.). Water-wise rice production. Proceedings of the International Work-shop on Water-wise Rice Production, 8-11 April 2002, Los Baños, Philippines. Los Baños (Philippines): International Rice Research Institute. p. 71-87.

WANG D et al. 2014. Optimizing hill seeding density for high-yielding hybrid rice in a single rice cropping system in south China. PLoS ONE 9: e109417. 